\title{
Impactes do Preço da Água na Agricultura no Perímetro Irrigado do Vale de Caxito ${ }^{12}$
}

\author{
Jaime Agostinho Jerónimo ${ }^{3}$, Pedro Damião Henriques ${ }^{4}$ e \\ Maria Leonor da Silva Carvalho ${ }^{5}$
}

Resumo: O aumento da pressão sobre os recursos hídricos tem levado muitos países a reconsiderarem os mecanismos utilizados na indução do uso eficiente da água, especialmente na agricultura irrigada. Estabelecer o preço correto da água é um dos mecanismos de tornar mais eficiente a alocação da água. O presente trabalho tem como objetivo a análise dos impactes económicos, sociais e ambientais de políticas de preço da água. A metodologia utilizada foi a Programação Linear, aplicada ao Perímetro Irrigado do Vale de Caxito, Província do Bengo, a $45 \mathrm{~km}$ de Luanda, que tem como fonte o rio Dande. Foram testados três cenários relativos a políticas de tarifação de água: tarifa volumétrica simples, tarifa volumétrica variável, e tarifa fixa por superfície. As principais conclusões mostram que, do ponto de vista do uso eficiente da água na agricultura, os melhores resultados obtêm-se com a tarifa volumétrica variável; do ponto de vista social, a tarifação volumétrica simples apresenta os melhores resultados; o método de tarifa volumétrica variável foi o mais penalizador, reduzindo rapidamente a área das culturas mais consumidoras de água, sendo o melhor do ponto de vista ambiental. Qualquer um dos métodos traz aspetos negativos relativamente à redução da margem bruta total.

Palavras-chaves: Recursos hídricos; Preço da água; Programação linear.

Abstract: Increased pressure on water resources has led many countries to reconsider the mechanisms used in the induction of efficient water use, especially for irrigated agriculture, a major consumer of water. Establishing the correct price of water is one of the mechanisms for more efficient allocation of water. This paper aims to analyze the economic, social and

1. Este artigo está escrito em português corrente utilizado em Portugal, em que não há correspondência de termos com o português utilizado no Brasil, mesmo para textos científicos em economia.

2. O trabalho dos autores Pedro Damião Henriques e Maria Leonor da Silva Carvalho é financiado por Fundos FEDER através do Programa Operacional Fatores de Competitividade - COMPETE (POCI-01-0145-FEDER-007659) e por Fundos Nacionais através da FCT - Fundação para a Ciência e a Tecnologia no âmbito do projeto UID/ECO/04007/2013.

3. UMA, Luanda, Angola. E-mail: jaimejeronimo2006@yahoo.com.br

4. Universidade de Évora, CEFAGE, Évora. Portugal. E-mail: pdamiao@uevora.pt

5. Universidade de Évora, ICAAM, Évora. Portugal E-mail: leonor@uevora.pt 
environmental impacts of water price policies. The methodology used is the linear programming, applied to the Irrigated Valley Caxito, in Bengo Province, 45 kilometers from Luanda, which has the river Dande as its source. Three scenarios concerning water price policies were tested: simple volumetric rate, variable volumetric rate and flat rate per surface. The main findings show that from the point of view of the efficient use of water in agriculture, the best results are obtained with variable volumetric rate; from the social point of view, the simple volumetric rate has the best results; the volume variable rate method proved to be the most penalizing, quickly reducing the area of most water consuming cultures, being the method in which the environmental objectives would be more readily achieved. Either methods bringnegative aspects in relation to the reduction of total gross margin.

Key-words: Water resources; Water price; Linear programming.

\section{Introdução}

A água é um recurso finito no planeta. Estima-se que a quantidade de recursos hídricos renováveis esteja na ordem de $47.000 \mathrm{~km}^{3} /$ ano, dos quais $41.000 \mathrm{~km}^{3}$ não são economicamente aproveitados (JOHANSSON, 2000 apud RESENDE et al., 2008). A quantidade de água bruta disponível para cada país é praticamente constante, se aliado ao crescimento mundial da população faz com que a avaliação de longo prazo da disponibilidade da água seja de 4.380 m3 por pessoa por ano em 2050 (JOHANSSON et al., 2002 apud RESENDE et al., 2008).

A grande maioria dos sistemas de agricultura utiliza as chuvas como principal fonte de abastecimento de água para as plantas. Naqueles locais em que a quantidade de precipitação durante $o$ ciclo de vida das plantas é insuficiente, e havendo água armazenada, esta pode ser utilizada para completar ou suplementar o fornecimento de água às plantas.

A irrigação é uma técnica alternativa que visa ao aumento da produtividade das culturas, especialmente em regiões áridas e semiáridas. Esta técnica pode ter grande impacto nas disponibilidades hídricas das fontes da água, devido ao imenso consumo de água requerido nos sistemas de irrigação, em especial nas regiões com elevada concentração de áreas irrigadas, principalmente na época da seca (COSTA, 1991).
A afetação eficiente dos recursos hídricos existentes é uma consequência da possível escassez deste recurso no futuro. $\mathrm{O}$ aumento desta eficiência pode ser conseguido através da cobrança de um valor pelo uso da água. Este mecanismo pode encorajar a conservação do recurso água. De acordo com Caramaschi et al. (2000), o uso racional da água, o aumento da sua produtividade e eficiência e a redistribuição dos custos sociais da sua utilização são induzidos através da cobrança pela sua utilização.

Angola possui um enorme potencial agrícola, combinado com um expressivo gradiente de situações edafoclimáticas. De acordo com o Relatório Económico de Angola (CEIC, 2011), o desafio atual do país é a diversificação da economia para diminuir a dependência do petróleo. E, sem dúvida, um dos sectores mais dinâmicos para o crescimento da economia angolana é o da agricultura, que apresentou uma taxa de crescimento real de $29 \%$, entre 2008 e 2009 (OGE, 2011), considerando-se que o regadio será no futuro um instrumento fundamental para a produção agrícola da nação Angolana. O combate à fome, a segurança alimentar e o aumento do contributo da agricultura para o PIB, são os sustentáculos fundamentais que devem contribuir para alavancar o desenvolvimento do sector agrário em Angola. Num país com elevada disponibilidade de recursos hídricos e com uma sazonalidade climática bem marcada, a água constitui um bem essen- 
cial ao desenvolvimento da agricultura durante o período seco, entre Maio e Outubro.

A agricultura em Angola necessita aproximadamente de $6.700 \mathrm{~m}^{3} / \mathrm{seg}$./ha de água, acrescido ao consumo hídrico pecuário estimado em $232.000 \mathrm{~m} 3 /$ dia (MINADER, 2002). No período anterior à independência foram implementados alguns esquemas de irrigação de grande dimensão, muitos deles associados a colonatos, de que são exemplos os construídos na província da Huíla. Os vários e longos anos de guerra civil, 1975-2002, que o país enfrentou, deixaram muitas das infraestruturas locais em ruínas. $\mathrm{O}$ Governo de Angola alinhado ao investimento interno, tem procurado mitigar a problemática da escassez de água em projetos assentes no âmbito da reconstrução pós-conflito.

De igual modo, surgiram várias obras de rega destinadas essencialmente à produção canavieira, de que são exemplos Caxito, Bom Jesus, Cavaco e Catumbela. Os regadios privados ou tradicionais (pequenos regadios) surgem quase sempre associados a cursos de água que visam apoiar a produção agrícola durante a época do cacimbo e disseminaram-se um pouco por todo o território.

O relançamento da atividade hidroagrícola foi, igualmente, uma das prioridades, pelo que se aprovou em Conselho de Ministros, na sua sessão de 4 de Março de 2005, o documento intitulado "Modelo de Gestão dos Perímetros Irrigados". Através da Resolução 7/05, de 1 de Abril, é constituída a SOPIR - Sociedade de Desenvolvimento dos Perímetros Irrigados, S.A., para gerir e supervisionar o património do Estado construído nos perímetros irrigados.

A irrigação como técnica que tem como finalidade aumentar e controlar a quantidade de água disponível para as plantas, permite um aumento da produtividade da agricultura e portanto da segurança alimentar, e uma diminuição do risco associado ao impacto negativo da variabilidade da precipitação (HENRIQUES et al., 2006). A irrigação pode ser vista como um complemento da precipitação e da humidade atmosférica permitindo manter um suprimento regular de água para as plantas.

Contrariamente ao que acontece na maior parte dos usos consumptivos, em que o uso da água reflete uma utilização final, na agricultura de regadio a água constitui um fator de produção agrícola, um consumo intermédio. Por isso, não existe uma procura direta da água, mas sim uma procura derivada, dependente da procura dos produtos nos mercados agrícolas. Como tal, a procura de água de rega está dependente do tipo de culturas, da tecnologia de irrigação e da rendibilidade das atividades agrícolas.

$\mathrm{O}$ acesso seguro a água de irrigação possui várias dimensões, nomeadamente produção rendimento/consumo, emprego, segurança alimentar e outros bens. Na dimensão produção a água para rega permite o aumento das colheitas, o aumento das áreas de produção, a intensificação dessa mesma produção, o aumento da diversificação das culturas. Em termos de rendimento/ consumo permite aumentos do rendimento da produção agrícola, aumentos do consumo alimentar das famílias, estabilização do rendimento familiar das explorações agrícolas e a redução do preço dos alimentos. Este acesso seguro a água de irrigação aumenta as oportunidades de emprego na agricultura e fora da agricultura e um aumento dos salários agrícolas. A irrigação permite ainda reforçar a disponibilidade de alimentos, a redução da insuficiência do consumo, redução do risco de más colheitas e dos efeitos sazonais da produção (HUSSAIN e HANJRA, 2003)

Dada a escassez da água, o seu uso sustentável passará certamente pela fixação de um preço para a sua utilização, marcando a importância crescente que as políticas de gestão da água vêm assumindo (SERAGELDIN, 1995; HENRIQUES et al., 2006). A fixação de um preço para a água na agricultura também pode ser considerada como um requisito para o uso sustentável dos recursos hídricos nos países em desenvolvimento.

Em diversas partes do mundo, a distribuição gratuita da água tem causado o uso irracional do recurso (WB, 1993). Relativamente ao consumo de água para a agricultura, a política de irrigação assume relevância especial uma vez que lida com a construção das infraestruturas de captação, armazenamento e distribuição, a manutenção dessas infraestruturas, a divisão da água pelos 
diferentes beneficiários e a adoção das tecnologias de rega.

Experiências antecedentes, em vários países e contextos mostraram que o aumento indiscriminado da oferta da água não estimulou o seu uso racional, levando a desperdícios, sem ter em conta os negativos impactos ambientais. O uso racional da água passa por políticas de preço da água.

Assim, este artigo tem como objetivo a análise dos impactes económicos, sociais e ambientais de políticas de preço da água no perímetro de rega do Caxito.

\section{Metodologia}

Para a determinação dos impactes económicos, sociais e ambientais de políticas de preço da água utilizámos um modelo de programação linear aplicado a uma exploração no perímetro de rega do Vale do Caxito.

A área de estudo faz parte do Perímetro de Rega do Vale de Caxito, que se situa na Província do Bengo, a $45 \mathrm{~km}$ de Luanda, na direção nordeste do território angolano, entre as latitudes $8^{\circ} 33^{\prime} \mathrm{S}$ e $8^{\circ} 37^{\prime} \mathrm{S}$ e as longitudes $13^{\circ} 32^{\prime}$ E e $13^{\circ} 42^{\prime}$ E. A área abrange cerca de 3.641 ha, estando limitada ao norte pelo Canal de Drenagem Sassa que se inicia nas proximidades e a jusante da Barragem Mabubas e segue para oeste paralelamente ao Rio Dande. O limite sul é definido pelo canal de irrigação de Caxito com 21,731 km de extensão, que conduz, gravitariamente, a vazão máxima de $3,87 \mathrm{~m}^{3} / \mathrm{s}$, derivada do rio Dande, com captação a jusante da Barragem de Mabubas. Esta barragem melhorou a proteção contra cheias. A oeste, a área é delimitada por uma estrada em aterro (dique, com revestimento primário) no sentido aproximado norte-sul. A leste, o limite é formado pela ponte sobre o rio Dande, na rodovia que une as cidades de Luanda, Quibaxe e Uíge, passando por Caxito.
A colheita dos dados necessários para a construção do modelo foi feita por inquérito à empresa agrícola, no caso a Agrolíder.

A área total da exploração é de 200 hectares com 177,5 hectares úteis, ocupados da seguinte forma:

- Fruteiras (Banana) - 77\% da área total da parcela (137 ha)

- Solanáceas (Tomate) - 17\% da área total da parcela (30 ha)

- Aliáceas (Alho, Cebola) - 3\% da área total da parcela (5,5 ha)

- Leguminosas (Feijão) - 2.9\% da área total da parcela (5 ha)

Qualquer uma destas culturas, à exceção da banana, permite a obtenção de 2 colheitas por ano, pelo que se consideraram para cada uma das atividades 2 épocas.

A bananeira como cultura permanente tem uma fase de instalação, tendo-se considerado apenas o ano cruzeiro para esta atividade, ou seja o ano em que a cultura já está em plena produção.

Foram consideradas duas unidades de utilização do solo, 1 e 2, a 1 para as culturais anuais, com uma área total de 40,5 hectares, e a 2 para a banana, com a área de 137 hectares.

Admitiu-se que toda a tração utilizada na exploração é alugada e que a mão-de-obra é temporária portanto contratada à medida das necessidades. Deste modo, estão presentes no modelo atividades de aluguer de tração e de contratação de mão-de-obra.

Para construir as restrições relativas às necessidades de tração e de mão-de-obra definiram-se, para cada uma das épocas culturais, períodos de tempo nos quais conjuntos de operações culturais podem ser executados. Para cada uma das épocas, o período 1 diz respeito às operações de preparação do terreno das culturas; no período 2 fazem-se as sementeiras e as plantações, as mondas, os amanhos culturais e as adubações de cobertura; o período 3 destina-se à colheita (Tabelas 1 e 2). 
Tabela 1. Necessidades de tração por hectare (horas)

\begin{tabular}{lccccc}
\multicolumn{1}{c}{ Cultura } & Feijão & Cebola & Alho & Tomate & Banana \\
\hline 1ª Época & & & & & \\
\hline Período 1. Preparação do terreno & 3,5 & 5 & 5 & 4 & - \\
Período 2. Sementeira, Plantação, amanhos & 3 & 3,5 & 3,5 & 3,5 & 2,5 \\
Período 3. Colheita & 1 & 2 & 2 & - & - \\
\hline 2a Época & & & & & \\
\hline Período 1. Preparação do terreno & 3,5 & 5 & 5 & 4 & - \\
Período 2. Sementeira, Plantação, amanhos & 3 & 3,5 & 3,5 & 3,5 & 2,5 \\
Período 3. Colheita & 1 & 2 & 2 & - & - \\
Colheita Banana & - & - & - & - & 16 \\
\hline
\end{tabular}

Fonte: Elaboração dos autores.

Tabela 2. Necessidades de mão-de-obra por hectare (UHT)

\begin{tabular}{lccccc}
\hline \multicolumn{1}{c}{ Cultura } & Feijão & Cebola & Alho & Tomate & Banana \\
\hline 1' Época & & & & & \\
\hline Período 2. Sementeira, Plantação, amanhos & - & 19 & 19 & 9 & - \\
Período 3. Colheita & 10 & 10 & 10 & 20 & - \\
\hline 2a Época & & & & & \\
\hline Período 2. Sementeira, Plantação, amanhos & - & 19 & 19 & 9 & - \\
Período 3. Colheita & 10 & 10 & 10 & 20 & - \\
Colheita Banana & - & - & - & - & 20 \\
\hline
\end{tabular}

Fonte: Elaboração dos autores.

As necessidades hídricas no período vegetativo das culturas são as seguintes: Banana - 1200$2200 \mathrm{~mm}$; Tomate - 400-600 mm; Alho e Cebola - 350-550 mm; Feijão - 350-500mm, tendo-se considerado na construção do modelo o valor médio destas necessidades para cada cultura.

De acordo com Hazell e Norton (1986), no uso da programação linear os pressupostos da aditividade (não são permitidos efeitos de interação entre atividades) e da proporcionalidade (margem bruta e as necessidades dos fatores de produção por unidade de atividade são constantes independentemente do nível de atividade praticada) têm de ser satisfeitos para garantir a linearidade das atividades.

Como os encargos fixos comuns e os fixos específicos não proporcionais à dimensão da produção não entram no cálculo da margem bruta, diferença entre a produção bruta e os encargos variáveis, existe uma rigorosa proporcionalidade entre a margem bruta e o nível da atividade.

A estrutura de custos a considerar no modelo depende do seu enquadramento no tempo (MARQUES, 1988). Um modelo de curto prazo inclui apenas custos variáveis. Já um modelo de longo prazo, assumindo a otimização dos ajustamentos no longo prazo, implica a consideração de todos os custos dos fatores de produção. Tomando o lucro como o excedente da margem bruta sobre os encargos fixos comuns, no curto prazo, durante uma campanha agrícola, para aumentar o lucro bastará aumentar a margem bruta.

O modelo a utilizar é um modelo de curto prazo pelo que a função objetivo corresponde a uma maximização da margem bruta total da exploração, sendo constituída pela diferença entre o somatório dos produtos brutos das atividades e o somatório dos diferentes encargos variáveis.

A produção bruta de uma cultura foi considerada como correspondendo à venda da sua produção, obtida durante um ciclo aos preços de mercado do ano base (2010/2011), na ocasião normal da venda. Os encargos variáveis das atividades vegetais incluem os gastos com sementes, plantas, adubos, fitofármacos, água de rega, custos com o aluguer de tração e contratação de mão-de-obra (Tabela 3). 
Tabela 3. Encargos e rendimentos das atividades incluídas no modelo

\begin{tabular}{lcccccc}
\hline \multicolumn{1}{c}{ Cultura } & $\begin{array}{c}\text { Produção } \\
\mathbf{( k g / h a )}\end{array}$ & $\begin{array}{c}\text { Preço } \\
\mathbf{( K z /} / \mathbf{k g})\end{array}$ & $\begin{array}{c}\text { Custo da tração } \\
\mathbf{( K z} / \mathbf{h})\end{array}$ & $\begin{array}{c}\text { Custo da mão de obra } \\
\mathbf{( K z} / \mathbf{U H T})\end{array}$ & $\begin{array}{c}\text { Custo da água } \\
\mathbf{( K z} / \mathbf{h a})\end{array}$ & $\begin{array}{c}\text { Outros custos variáveis } \\
(\mathbf{K z} / \mathbf{h a})\end{array}$ \\
\hline Feijão & 2500 & 100 & 3500 & 6500 & 600 & 41.800 \\
Cebola & 15.000 & 75 & 3500 & 6500 & 600 & 558.700 \\
Alho & 6000 & 200 & 3500 & 6500 & 600 & 399.700 \\
Tomate & 7000 & 100 & 3500 & 6500 & 600 & 241.300 \\
Banana & 20.000 & 60 & 3500 & 7000 & 600 & $420.183,48$ \\
\hline
\end{tabular}

Fonte: Elaboração dos autores.

Ao fazer a formulação matemática do modelo assume-se que o agricultor tem por objetivo a maximização do lucro, a partir de um conjunto finito de processos produtivos $n$, representando cada um, uma combinação particular de fatores de produção usada para produzir a atividade unitária. Os agricultores atuam em mercados competitivos para os produtos e os fatores de produção.

A formulação do modelo para a exploração em causa é dada por:

$$
\operatorname{Max} \mathrm{Z}=\sum_{j} p_{j} P_{j}-p t T-p m M-C A-C V
$$

sujeito a

Restrições de utilização da terra:

$$
\sum_{j} X_{j} \leq b s
$$

Restrições de balanço das culturas:

$$
-r_{j} X_{j}+P_{j} \leq 0
$$

Restrições de utilização de tracção mecânica:

$$
\sum_{j} a t_{j} X_{j}-T \leq 0
$$

Restrições de utilização de mão de obra:

$$
\sum_{j} a m_{j} X_{j}-M \leq 0
$$

Restrição relativa ao consumo de água pelas culturas:

$$
\sum_{j} h_{j} X_{j}-A G \leq 0
$$

Restrição relativa ao custo da água:

$$
\sum_{j} t h X_{j}-C A \leq 0
$$

Restrição relativa ao apuramento dos outros custos variáveis:

$\sum_{j} p v_{j} X_{j}-C V \leq 0$

Condições de não negatividade

$P_{j}, X_{j} \geq 0$

Neste modelo as variáveis são:

$X_{j}$-área ocupada pela cultura j em hectares;

$P_{\mathrm{j}}$ - rendimento da cultura j em $\mathrm{kg}$;

$T$ - aluguer de tração em horas;

$M$ - contratação de mão-de-obra em UHT;

$A G$ - consumo total de água pelas culturas em milhares de $\mathrm{m}^{3}$;

$C A$ - custo total da água em milhares de Kz;

$\mathrm{CV}$ - outros custos variáveis em milhares de Kz.

Os parâmetros do modelo são:

$p_{\mathrm{j}}$ - preço da cultura $j$ em milhares de $\mathrm{Kz} / \mathrm{kg}$;

pt - preço da tração em milhares de Kz/hora;

pm - preço da mão de obra em milhares de

$\mathrm{Kz} / \mathrm{UHT}$;

$r_{\mathrm{j}}$-produtividade da cultura j em $\mathrm{kg} / \mathrm{ha}$;

$a t_{j}$ - necessidades unitárias de tração da atividade $j$, em horas por hectare;

$a m_{\mathrm{j}}$ - necessidades unitárias de mão de obra da atividade $j$, em UHT por hectare;

$h_{\mathrm{j}}$ - necessidades unitárias de água da atividade $j$, em milhares de $\mathrm{m}^{3}$ por hectare;

th - tarifa de regadio aplicada à atividade em milhares de Kz por hectare;

$p v_{\mathrm{j}}$ - outros custos variáveis da atividade $\mathrm{j}$ em milhares de $\mathrm{Kz}$ por hectare;

bs - disponibilidade de terra em hectares. 
A função objetivo (1) traduz a maximização da margem bruta total da exploração em milhares de $\mathrm{Kz}$, e é dada pela soma dos valores das várias produções vegetais deduzido dos custos variáveis das atividades.

As restrições (2) definem a utilização da terra. A terra é desagregada por unidades de utilização e por épocas de colheita, e permite-se a transferência de terra entre unidades de utilização. Cada equação reflete as necessidades de terra das várias atividades vegetais.

As restrições de balanço das culturas (3) fazem o balanço, para cada atividade, entre a área cultivada e a produtividade da cultura.

As restrições (4) e (5) referem-se à utilização de tração mecânica e mão-de-obra, respetivamente, pelas atividades produtivas. São elaboradas de modo a garantirem a satisfação das necessidades das atividades vegetais ao longo do ano e a apurarem o consumo total desses dois fatores produtivos.

A restrição relativa ao consumo de água pelas culturas (6) contempla as necessidades unitárias de água das atividades e permite determinar a quantidade total de água necessária para garantir o plano cultural ótimo.

Já a restrição (7) permite apurar o custo total da água. A restrição (8) apura os restantes custos variáveis da exploração.

O modelo anterior pressupõe uma tarifa de regadio aplicada à atividade (milhares de $\mathrm{Kz}$ por hectare), que traduz a situação atual.

Para as diferentes simulações de tarifas da água (tarifas volumétricas fixa e variável), o modelo precisa de sofrer alguns ajustamentos, devidamente especificados no capítulo da análise de resultados.

Para dar solução ao modelo estabelecido de Programação Linear com 35 variáveis e 33 restrições, utilizou-se o software LINDO (Linear Interactive and Discrete Optimizer, 1996) que tem a função de resolver sistemas de equações lineares com ajuda do algoritmo iterativo Simplex.

\section{Análise dos resultados}

Os cenários testados para avaliar os efeitos das políticas de tarifação de água no perímetro em estudo são: tarifa volumétrica simples (TVS), tarifa volumétrica variável (TVV), e tarifa fixa por superfície (TFS). Este último método, método de tarifação da água não volumétrico, é um método com grande facilidade na sua aplicação, enquanto os outros dois métodos volumétricos são métodos que levam em conta a justiça na sua aplicação.

Em cada um dos cenários analisaram-se os parâmetros mais significativos do ponto de vista das atividades agrícolas e dos impactos socioeconómicos e ambientais.

Relativamente às atividades agrícolas apresentam-se as variações nos níveis das atividades ocorridas devido à aplicação das tarifas.

O impacto económico é analisado através da receita total da aplicação da tarifação da água, e ainda o seu impacto na margem bruta total da empresa.

Do ponto de vista social, analisa-se a quantidade de mão-de-obra total utilizada para os diferentes cenários.

O impacto ambiental é analisado em termos de consumo de água.

\subsection{Método com tarifa fixa por superfície}

A tarifa fixa por superfície corresponde à aplicação de um preço fixo por unidade de área, independentemente da cultura e da quantidade de água utilizada/recebida. É um método mais simples e mais barato de aplicar, que promove a equidade vertical, ou seja maiores explorações com maiores áreas irrigadas pagam mais do que os pequenos agricultores. Contudo, trata-se de um método que não incentiva os agricultores à poupança de água. Na situação atual, esta tarifa corresponde a $600 \mathrm{Kz} /$ hectare.

Com a aplicação deste método verifica-se uma grande rigidez na ocupação cultural, e 
consequentemente, no consumo da água e na quantidade de mão de obra utilizada, como se pode verificar pelas Figuras 1, 2 e 3 .

A composição da ocupação cultural da área da empresa revela-se muito estável até aos 256 milhares $\mathrm{kz} /$ hectare, com a banana a ocupar $77 \%$ da área (137 ha), o tomate com 17\% da área (30 ha), a cebola e o alho com $2 \%$ (2,625 ha cada uma das culturas) e o feijão com 3\% da área (5,25 ha) (Figura 1).

Esta tarifa de 256 milhares $\mathrm{Kz} / \mathrm{ha}$ representa a tarifa limite da água para todas as culturas à exceção da banana que continua a ser cultivada (137 ha).

A redução a nível do consumo de água é abrupta e de cerca de $14 \%$, bem como a da quantidade de mão-de-obra utilizada (redução de $44 \%$ ), reduções estas verificadas para uma tarifa de 256 milhares Kz/ha, e resultantes do abandono de uma parte da ocupação cultural da área da empresa (Figuras 2 e 3 )
A Figura 4 mostra a evolução da receita da água em função da tarifa de regadio aplicada. De salientar que esta receita da água cresce até um montante da tarifa igual a 200 milhares $\mathrm{Kz} / \mathrm{ha}$, valor a partir do qual diminui o consumo de água, diminuindo igualmente a receita da água. A diminuição do consumo da água deve-se ao abandono da área das culturas do tomate, feijão, cebola e alho. A receita da água volta a crescer a partir dos 300 milhares $\mathrm{Kz} / \mathrm{ha}$, valor da tarifa que compensa a perda da receita devida ao não cultivo de toda a área disponível.

Ao se introduzir o método de tarifação fixa por superfície de água no perímetro irrigado do vale Caxito, verifica-se uma diminuição significativa na margem bruta da empresa Agrolíder de cerca de $98 \%$ entre a margem bruta obtida quando a tarifa é 0 e a margem bruta para a tarifa máxima de 550 milhares Kz/ha (Figura 5).

Figura 1. Área ocupada pelas culturas (\%) para diferentes níveis de preços da água (milhares Kz/ha) (TFS)

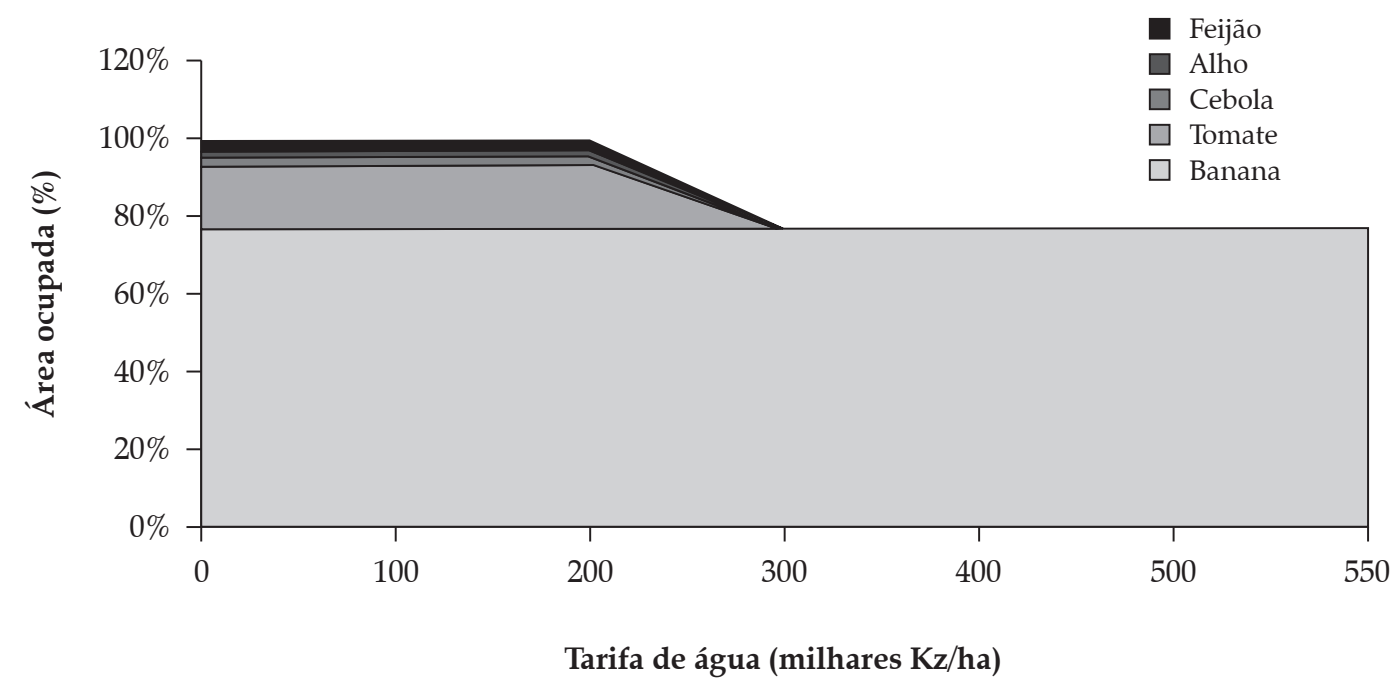

Fonte: Elaboração dos autores. 
Figura 2. Consumo total de água (milhares de $\mathrm{m}^{3}$ ) para diferentes valores da tarifa da água (TFS)

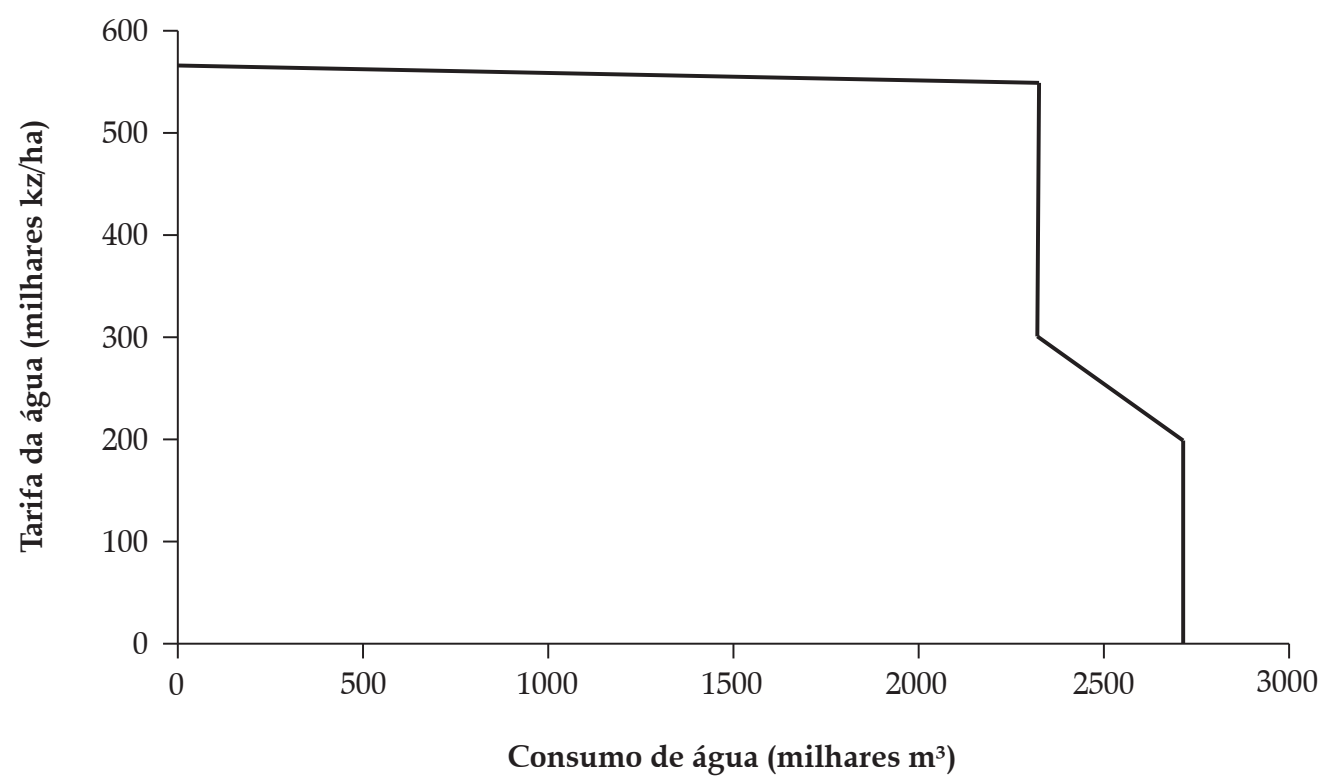

Fonte: Elaboração dos autores.

Figura 3. Mão-de-obra (UHT) para diferentes valores da tarifa da água (TFS)

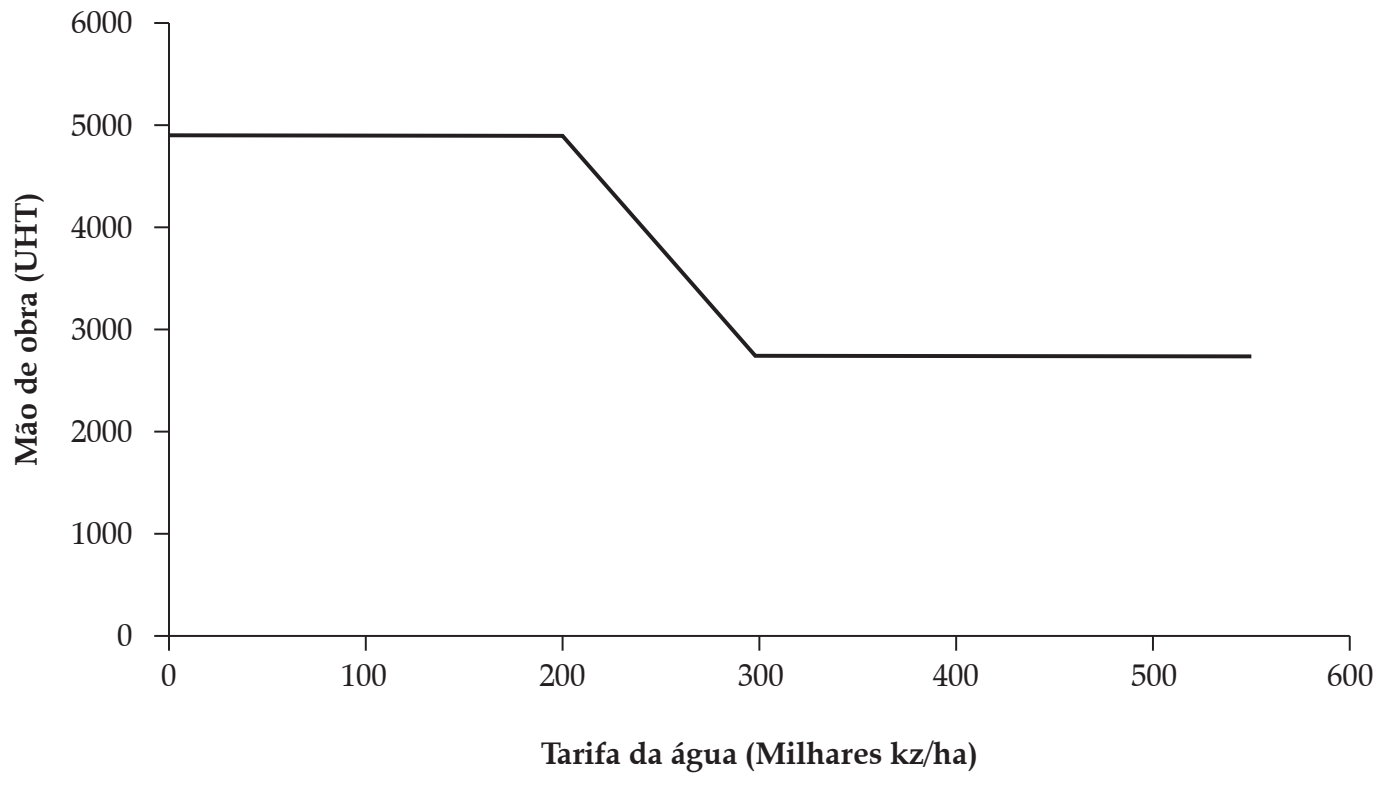

Fonte: Elaboração dos autores. 
Figura 4. Receita total da água (milhares de Kz) para diferentes valores da tarifa da água (TFS)

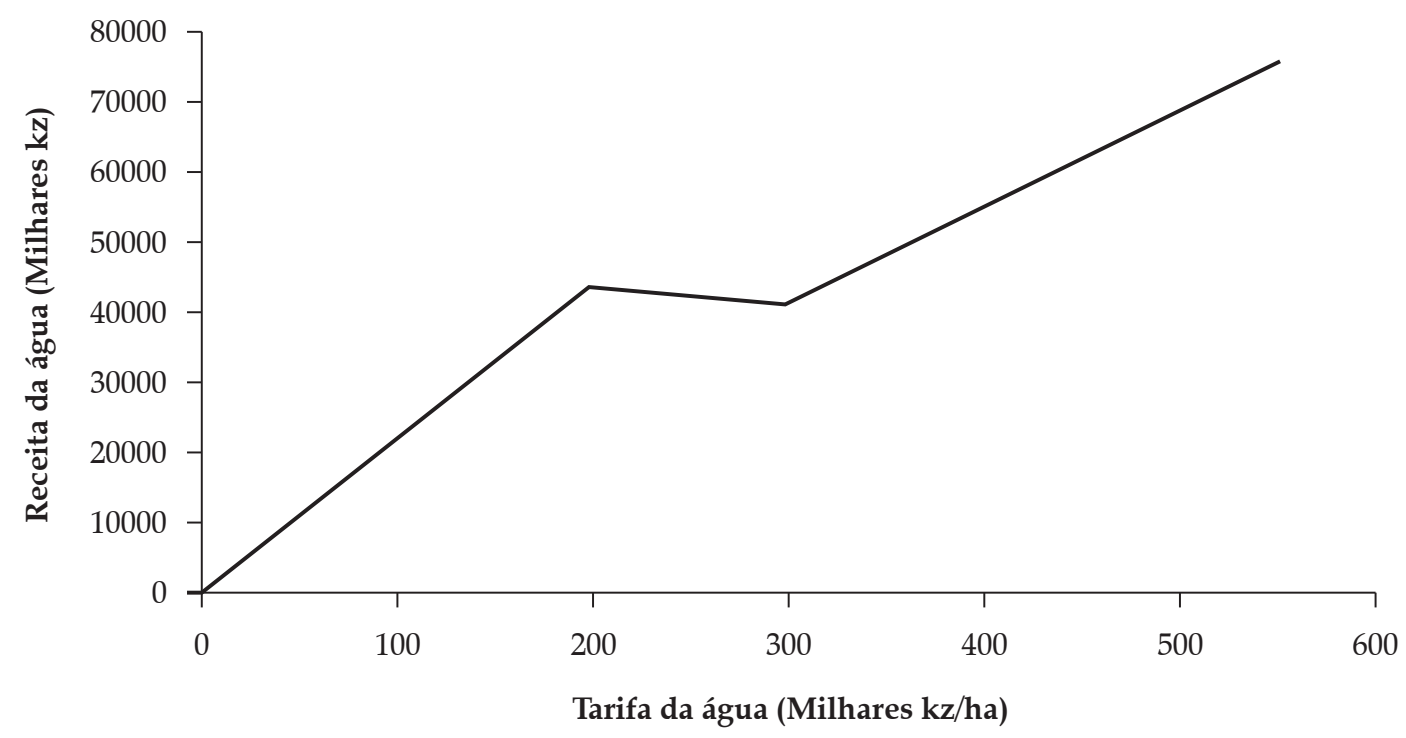

Fonte: Elaboração dos autores.

Figura 5. Margem bruta (milhares de kz) para valores da tarifa da água (TFS)

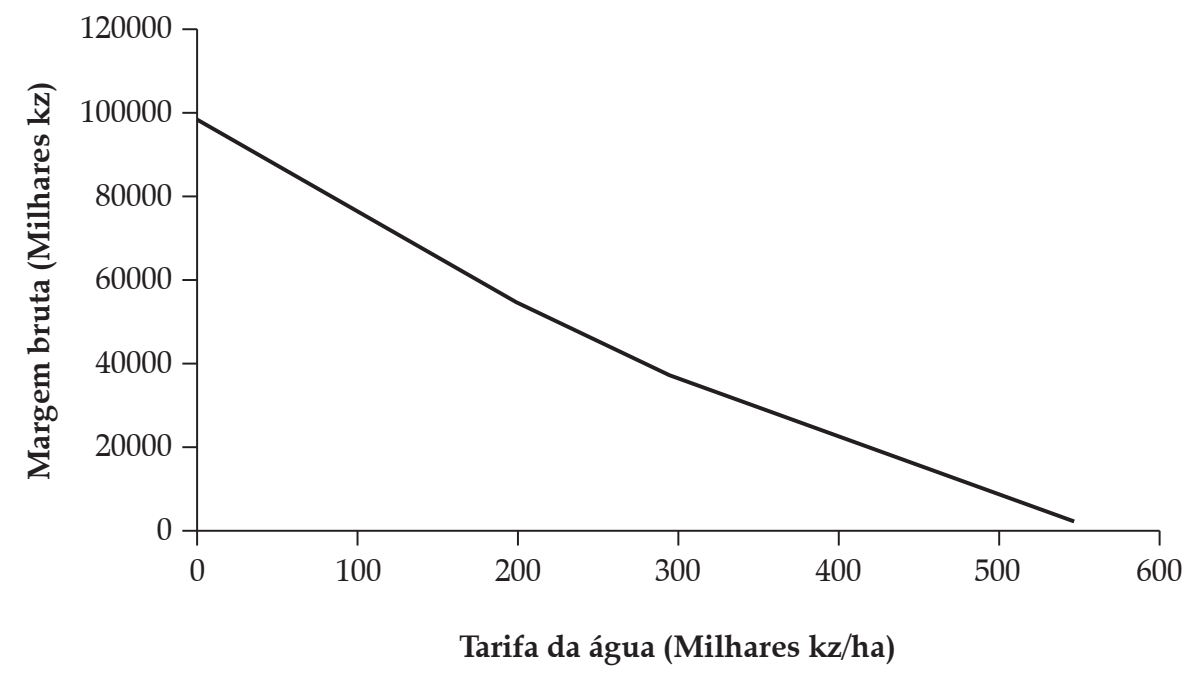

Fonte: Elaboração dos autores.

\subsection{Métodos com tarifa volumétrica}

Os métodos de tarifação volumétrica da água aplicam uma tarifa por unidade de água, valor que se encontra diretamente relacionado com a quantidade de água utilizada.

No caso da tarifa volumétrica simples o valor por unidade de água é constante qualquer que seja a quantidade. Para a tarifa volumétrica variável, quanto maior a quantidade de água recebida, maior o preço a pagar por unidade, ou seja as quantidades de água agrupam-se por escalões de preços crescentes.

Estes sistemas promovem a equidade horizontal que tem a ver com a igualdade da 
distribuição e dos encargos com a água entre os utilizadores que têm acesso a essa mesma água.

Estes métodos são mais exigentes ao nível da sua aplicação uma vez que exigem uma monitorização da água recebida por cada utilizador, e também uma autoridade supervisionadora do funcionamento do sistema, que estabeleça preços e receba o valor das tarifas. Portanto, um sistema destes apresenta custos de monitorização e de administração que podem ser bastante elevados.

A tarifação da água pelo método da tarifa volumétrica simples mostra efeitos na composição da ocupação cultural a partir de valores de preço da água bastante baixos $\left(8 \mathrm{Kz} / \mathrm{m}^{3}\right)$, como se pode ver na Figura 6.

A banana deixa de se fazer a partir de um preço da água de $8 \mathrm{Kz} / \mathrm{m}^{3}$, devido às elevadas necessidades hídricas desta cultura. A margem bruta da cultura não compensa a utilização de água com preços mais elevados.

A partir dos $8 \mathrm{Kz} / \mathrm{m}^{3}$, observa-se uma transferência da área ocupada pela banana para a cultura do tomate, que apresenta um aumento de área da ordem dos $57 \%$, do feijão (10\%), do alho $(5 \%)$ e da cebola (5\%).
Para as restantes culturas, o preço limite da água, ao qual corresponde o abandono total das culturas é de $52,77 \mathrm{Kz} / \mathrm{m}^{3}$.

O método com tarifa volumétrica variável reveste-se de alguma complexidade na sua aplicação, mas é mais eficiente no que respeita á penalização das culturas mais consumidoras de água.

A aplicação deste método foi simulada com tarifas variáveis de acordo com o nível de consumo de água das culturas, tendo-se constituído três escalões de consumo de água:

- 10 escalão: AGUA1<1000 (milhares de $\mathrm{m}^{3}$ );

- 2o escalão: AGUA2 <1000 (milhares de $\mathrm{m}^{3}$ );

- 3o escalão: AGUA3<1000 (milhares de $\mathrm{m}^{3}$ ).

As tarifas da água crescem do $1^{\mathrm{o}}$ para o $3^{\mathrm{o}}$ escalão.

Para facilitar a elaboração dos gráficos, utilizaram-se apenas os valores das tarifas respeitantes ao primeiro escalão. Esta metodologia facilitou também a comparação deste método de tarifação com o método de tarifação volumétrica fixa.

A Figura 7 mostra a evolução da área ocupada pelas culturas em função da tarifa variável

Figura 6. Área ocupada pelas culturas (\%) para diferentes níveis de preços da água $\left(\mathrm{Kz} / \mathrm{m}^{3}\right)(\mathrm{TVS})$

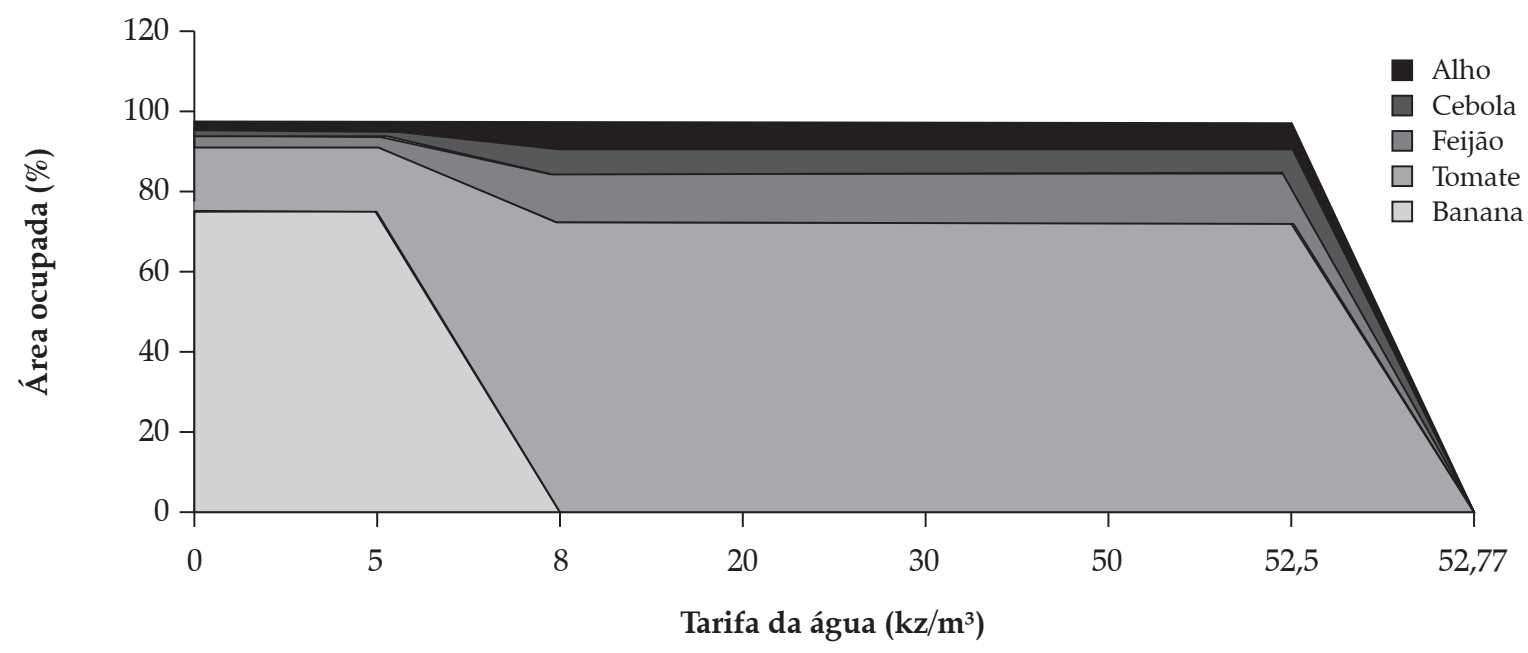

Fonte: Elaboração dos autores. 
Figura 7. Área ocupada pelas culturas (\%) para diferentes níveis de preços da água $\left(\mathrm{Kz} / \mathrm{m}^{3}\right)(\mathrm{TVV})$

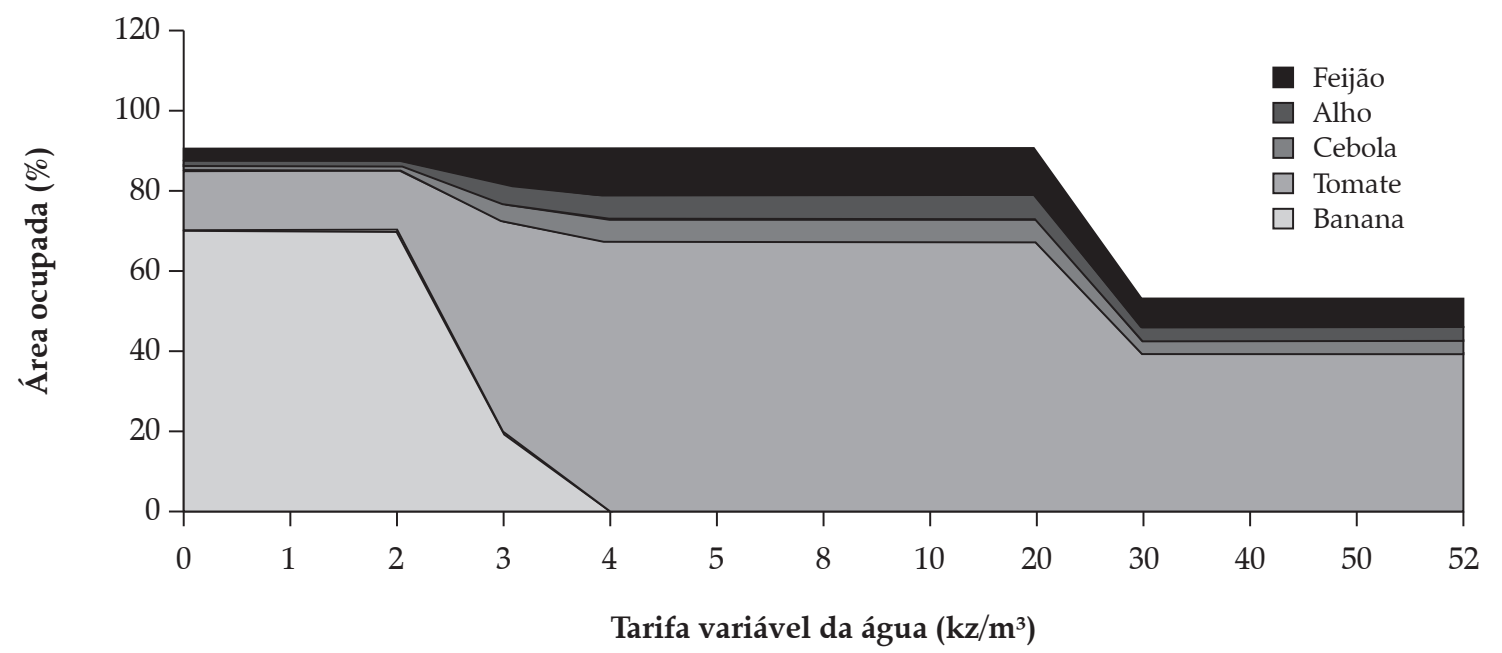

Fonte: Elaboração dos autores.

aplicada por $\mathrm{m}^{3}$ de água consumido. Os efeitos na composição da ocupação cultural começam quando a tarifa da água é de $3 \mathrm{Kz} / \mathrm{m}^{3}$ no $1^{\text {o }}$ escalão, $6 \mathrm{Kz} / \mathrm{m}^{3}$ no $2^{\circ}$ e $9 \mathrm{Kz} / \mathrm{m}^{3}$ no $3^{o}$. Verifica-se uma redução significativa na área da cultura de banana, passa de 137 ha para 38,5 ha, o que corresponde a uma redução da área de cerca de $72 \%$. Esta cultura exige grandes quantidades de água de rega, pelo que é mais penalizada.

A partir desta mesma tarifa variável, observa-se uma ligeira transferência da área ocupada pela banana para a cultura do tomate, que apresenta um aumento de área da ordem dos $41 \%$, do feijão $(7 \%)$, do alho (4\%) e da cebola (4\%). A banana deixa de ser cultivada para uma tarifa de $4 \mathrm{Kz} / \mathrm{m}^{3}$ no $1^{\mathrm{o}}$ escalão, $8 \mathrm{Kz} / \mathrm{m}^{3}$ no $2^{\mathrm{o}}$ e $12 \mathrm{Kz} / \mathrm{m}^{3}$ no $3^{\mathrm{o}}$, sendo toda a área transferida para as restantes culturas.

A ocupação cultural modifica-se para um preço da água de $30-60-90 \mathrm{Kz} / \mathrm{m}^{3}$, verificando-se uma redução na área do feijão, cebola, alho e tomate.

A tarifa limite para o método da TVV é de $52 \mathrm{Kz} / \mathrm{m}^{3}$ para o $1^{\mathrm{o}}$ escalão, não sendo importantes os valores da tarifa para o $2^{\mathrm{o}}$ e $3^{\circ}$ escalões, uma vez que a área cultivada e as culturas praticadas, e respetivas áreas, não exigem mais do que a água considerada neste escalão.
Quando se procede à comparação entre os dois métodos de tarifação volumétrica da água, e relativamente à área ocupada pelas culturas em cada um dos casos, verifica-se que com o método de tarifação volumétrica variável as reduções nas áreas das culturas começam a verificar-se para tarifas da água do $1^{\mathrm{o}}$ escalão mais baixas do que no método de tarifação volumétrica simples, sendo por isso a cultura da banana, muito mais exigente em água, penalizada para tarifas mais baixas da água.

Na Figura 8 comparam-se os consumos de água para os dois métodos, verificando-se que a redução do consumo de água ocorre muito mais rapidamente para o método de tarifação volumétrica variável do que para o de tarifação volumétrica simples. Os elevados preços da água para o $2^{\mathrm{O}}$ e 3 e escalões no método TVV penalizam mais rapidamente as culturas mais exigentes em água, como é o caso da banana, reduzindo a sua área, portanto diminuindo as necessidade gerais de água.

Observa-se que a introdução da tarifa volumétrica simples de $52 \mathrm{Kz} / \mathrm{m}^{3}$, gera uma redução no consumo total de água de $37 \%$ relativamente ao consumo inicial. Já para a tarifa volumétrica variável do mesmo montante no primeiro escalão, regista-se uma quebra no consumo de água de $63 \%$. Neste contexto, o método de tarifação volu- 
Figura 8. Consumo total de água (milhares de $\mathrm{m}^{3}$ ) para os métodos de tarifação volumétrica

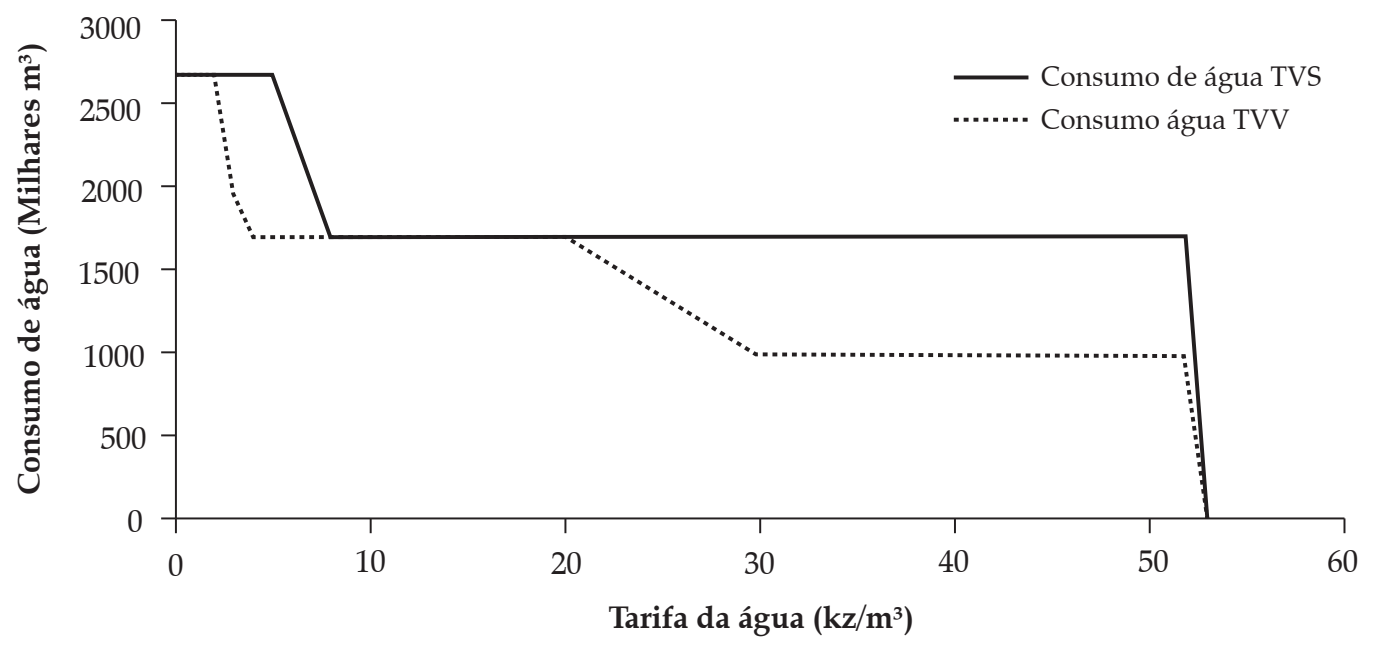

Fonte: Elaboração dos autores.

métrica variável age de uma forma mais acentuada que o método de tarifação volumétrica simples.

Quanto ao método de tarifação fixa de superfície, com uma tarifa de 550 milhares kz/ha, correspondendo a $32,4 \mathrm{Kz} / \mathrm{m}^{3}$, o consumo de água é reduzido em $14 \%$ relativamente ao consumo com tarifas mais baixas.
Com a existência de uma política de preço da água na agricultura, a entidade responsável pela sua aplicação regista um aumento da receita da água com um comportamento idêntico nos dois métodos volumétricos, atingindo no entanto valores mais elevados na tarifação volumétrica variável (Figura 9)

Figura 9. Receita total da água (milhares de Kz) para os métodos de tarifação volumétrica

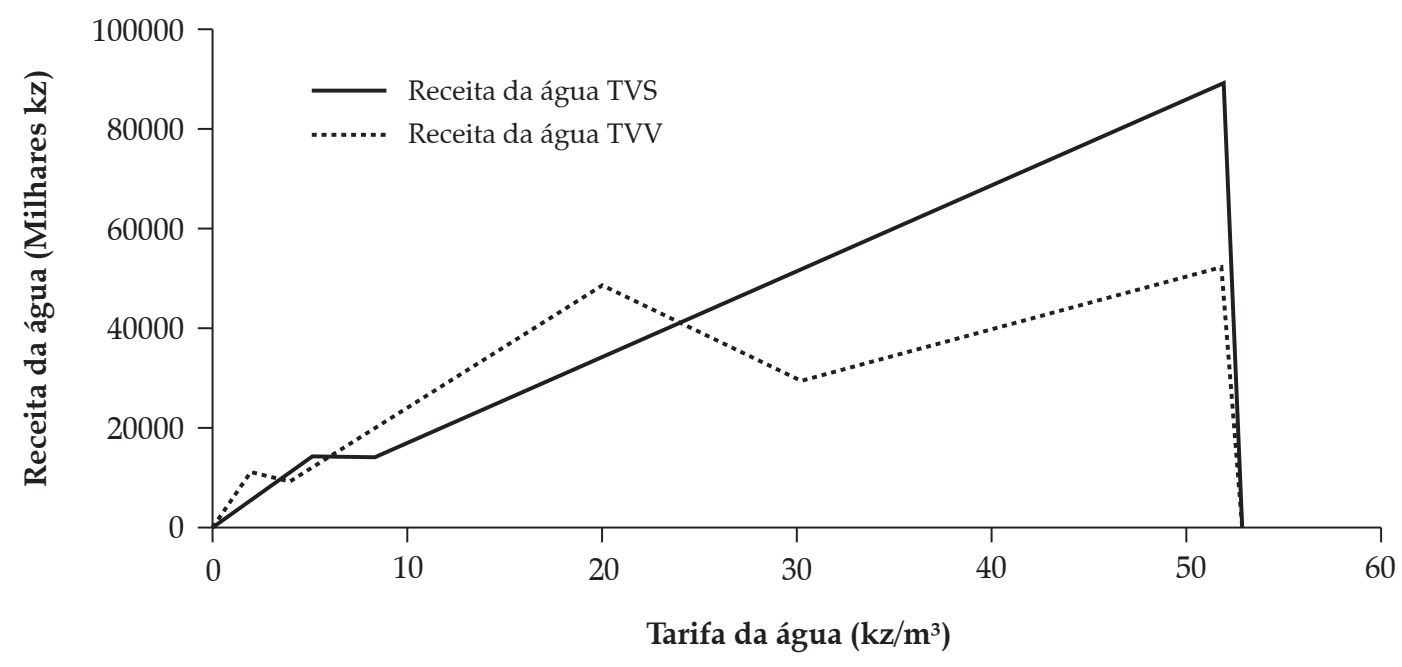

Fonte: Elaboração dos autores. 
É óbvio que com a proposta de fixação de uma tarifa justa para o regadio no perímetro irrigado do vale de Caxito, o rendimento da empresa Agrolíder sofre uma redução, quer seja pela própria tarifa em si, quer pela modificação das culturas realizadas. Deste modo, analisando a Figura 10, que compara a evolução da margem bruta total quando é aplicado o método de tarifação volumétrica simples com o variável, pode-se con- cluir que a margem bruta da empresa diminui mais acentuadamente na tarifação volumétrica variável do que na simples, para valores mais baixos da tarifa da água. Esta redução na margem bruta para tarifas mais elevadas é muito semelhante para os dois tipos de tarifação volumétrica.

A Figura 11 mostra a evolução da mão-de-obra face às tarifas da água. Os acréscimos das necessidades de mão-de-obra para tarifa volumétrica

Figura 10. Margem bruta (milhares de Kz) para os métodos de tarifação volumétrica

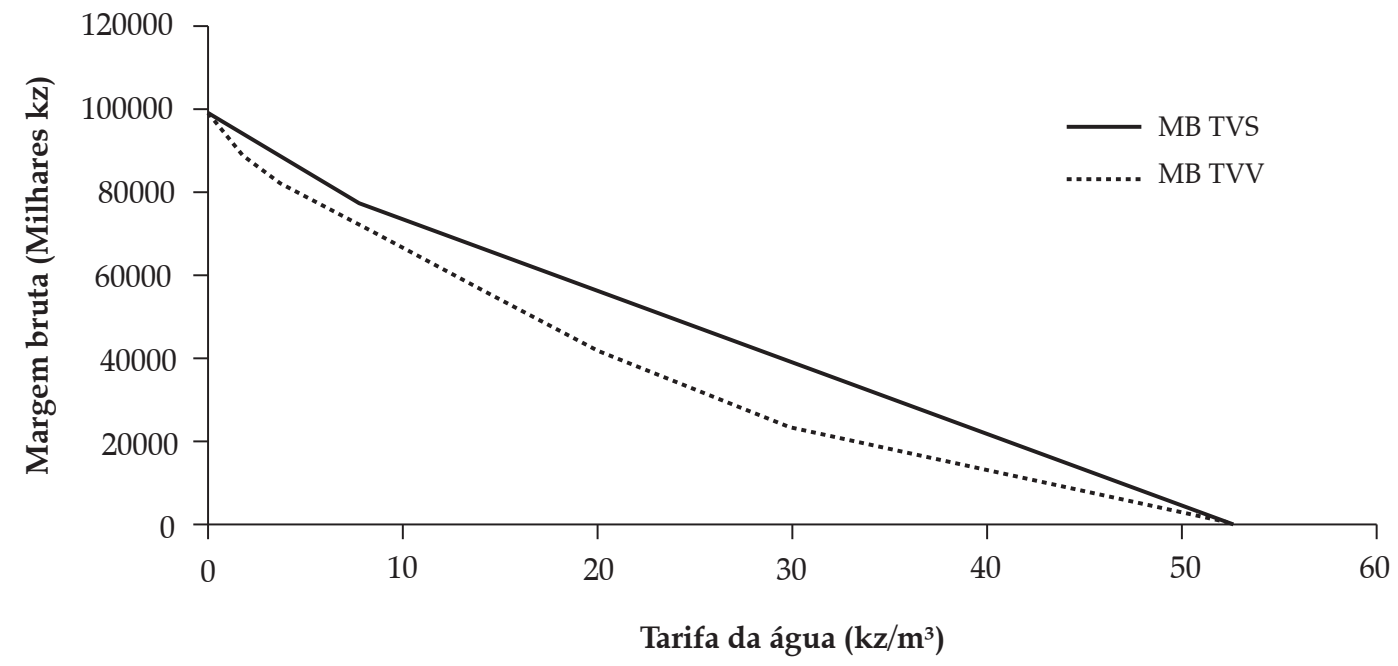

Fonte: Elaboração dos autores.

Figura 11. Mão-de-obra (UHT) para os métodos de tarifação volumétrica

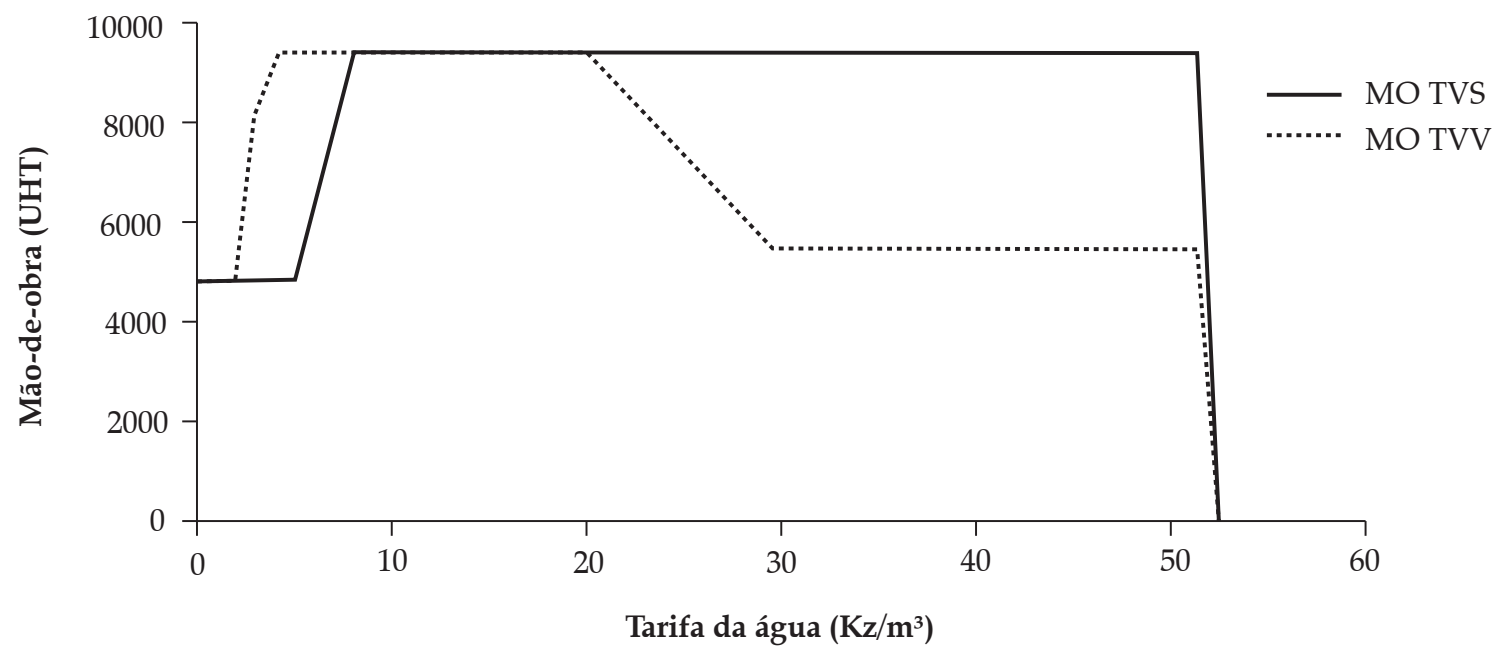

Fonte: Elaboração dos autores. 
simples só acontecem a partir de $8 \mathrm{Kz} / \mathrm{m}^{3}$ enquanto que para as tarifas volumétricas variáveis esse acréscimo dá-se para uma tarifa de $3 \mathrm{Kz} / \mathrm{m}^{3}$ no primeiro escalão $\left(6 \mathrm{Kz} / \mathrm{m}^{3}\right.$ no segundo escalão e $9 \mathrm{Kz} / \mathrm{m}^{3}$ no terceiro escalão).O decréscimo das necessidades de mão-de-obra para a tarifação volumétrica variável não é tão abrupta como a do outro método, uma vez que se dá uma redução da área cultivada para valores mais elevados da tarifa.

Os valores da variação da mão-de-obra devem ser tomados como indicadores do impacto social da aplicação da proposta de fixação do preço da água nas áreas de regadio da empresa Agrolider.

A política de tarifação da água para a irrigação exerce de igual modo um impacto importante no meio ambiente, uma vez que a utilização da água está fortemente ligada à intensificação da atividade agrícola.

Depois da análise dos resultados relativamente ao consumo da água, constata-se que os acréscimos no preço da água são conducentes a significativas reduções no consumo à medida que aumenta a tarifa, e isto acontece em todos os métodos analisados no presente trabalho. Portanto, qualquer política de preço da água levará a uma diminuição da intensificação da atividade agrícola, reduzindo assim o impacto da agricultura no ambiente.

\section{Conclusões}

Em termos de recursos hídricos superficiais, Angola possui enormes potencialidades, com quarenta e sete bacias hidrográficas estendendo-se por uma área de influência que ocupa praticamente toda a sua extensão territorial, o que pode ser considerado um potencial hídrico excecional.

Para os recursos subterrâneos não se têm feito estudos aprofundados, embora seja a principal fonte primária de abastecimento em determinadas regiões. Angola detém a segunda maior disponibilidade hídrica da região austral, apenas ultrapassada pela República Democrática do Congo.
Por certo, a água é um bem naturalmente renovável. Porém, na prática, o aumento populacional tem ocorrido em níveis superiores aos tolerados pela natureza, o que resultará, em pouco tempo, em stress do sistema hídrico.

Tendo em conta os cenários para avaliar os efeitos das políticas de tarifação de água no perímetro irrigado de vale de Caxito, depois de feitas as simulações concluiu-se que entre os métodos de tarifação volumétrica, o de tarifação variável provoca uma redução mais intensa na área ocupada pelas culturas e observa-se uma maior penalização da cultura de Banana em relação às outras. Com o método de tarifação fixa por superfície não se verifica redução na área da banana, pois com a aplicação desta tarifa ao hectare, não há incentivos para que não se continue com as culturas exigentes em água.

Do ponto de vista do uso eficiente da água na agricultura, os melhores resultados obtêm-se com a tarifa volumétrica variável, seguindo-se a tarifa volumétrica simples.

Com a implementação da política de tarifação da água de regadio a empresa sofreria uma redução no rendimento, quer seja pela própria tarifa em si, quer pela modificação das culturas realizadas.

No que tange ao acréscimo das necessidades de mão-de-obra, portanto do ponto de vista social, a tarifação volumétrica simples apresenta melhores resultados, seguindo-se o de tarifa volumétrica variável;

A empresa em estudo consome quantidades maiores de água para baixos níveis de preço da água.

O método de tarifa volumétrica variável mostrou ser o mais penalizador, reduzindo mais rapidamente a área das culturas mais consumidoras de água, sendo por isso o método em que os objetivos ambientais seriam mais facilmente atingidos, embora com custos mais elevados.

O método de tarifa fixa, sendo o de mais fácil implementação, é o que traz menores impactos ambientais, económicos e sociais.

Como esperado, qualquer um dos métodos traz aspetos negativos na sua aplicação no que toca à redução da margem bruta total. 
A proposta de determinação do preço da água no perímetro irrigado de Caxito para o uso eficiente do recurso provocaria certo alarme por parte dos agricultores desta zona na possível degradação das suas condições económicas, pelo facto do aumento da tarifação de água. Em face deste cenário, muitos agricultores prefeririam abandonar a atividade agrícola.

No sector ambientalista desta localidade, seguidos pela maioria da população consideram oportuna justa e urgente à aplicação de uma política que proteja este recurso tão importante para a humanidade e gerações vindouras dos abusos, que consciente ou inconscientemente alguns sectores desta atividade cometem sobre o mesmo.

\section{Referências}

CARAMASCHI, E., CORDEIRO NETO, O. e NOGUEIRA, J. O preço da água para irrigação: um estudo comparativo de dois métodos de valoração económica contingente e dose-resposta. Cadernos de Ciência E Tecnologia, v. 17, n. 3, p. 59-81, 2000.

CEIC - Centro de Estudos e de Investigação Científica da Universidade Católica de Angola. Relatório Económico de Angola, 2011.

COSTA, M. H. Modelo de optimização dos recursos hídricos para a irrigação, conforme a época de plantio. Viçosa. UFV. Dissertação de Mestrado, 1991.

HAZELL, P. B. R. e NORTON, R. D. Mathematical Programming for Economic Analysis in Agriculture, Macmillan, New York, 1986.

HENRIQUES, P. et al. Direito de Acesso à Água: Princípios Económicos para o seu Usufruto na
Agricultura. In: BRANCO, M., CARVALHO, M. L. e REGO, C. Economia com Compromisso: ensaios em memória de José Dias. Cefag-UE, Évora: Universidade de Évora, 2006 , p. 29-55.

HUSSAIN, I. e HANJRA, M. Does irrigation water matter for rural poverty alleviation? Evidence from South and South-East Asia. Water, Policy, v. 5, n. 5, p. $429-442,2003$.

JOHANSSON, R. C. Pricing Irrigation water: a literature survey. The World Bank Rural Development Department, Policy Research working paper, Washington D.C., 2000, p. 1-80.

.et al. Pricing and allocation of irrigation water: a review of theory and practice. Water Policy, v. 4, n. 2, p. 173-199, 2002.

MARQUES, C. A. F. Portuguese entrance into the European Community - implications for dryland agriculture in the Alentejo region, PhD Thesis, Purdue University, West Lafayette, U.S.A., 1988.

MINADER - Ministério da Agricultura e Desenvolvimento Rural. Relatório sobre o contributo da Agricultura Irrigada. Angola, 2002.

OGE, Relatório Fundamentado do Orçamento Geral do Etado, Angola, 2011.

RESENDE FILHO, M. A. et al. Precificação da água em projetos de irrigação: uma aplicação do método paramétrico de estimação de uma função insumodistância. In: Anais congresso da SOBER, Rio Branco, Brasil, 2008.

SERAGELDIN, I. Evaluating Environmentally Sustainable Development", in Evaluating and Development. In: Proceedings do 1994 World Bank Conference, 1995.

WORLDBANK. Sub Saharan Africa Hydrological Assessment SADCC Countries, Country Report: Angola, 1993. 